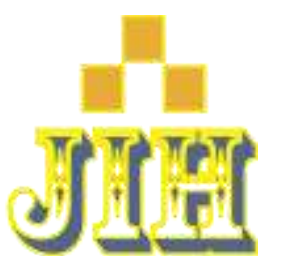

\title{
Modernisasi dan Penguatan Perekonomian 'Aisyiyah Pada Masa Kepemimpinan Siti Baroroh Baried 1965-1985 M
}

\author{
Halimah Nur Febryani \\ UIN Sunan Kalijaga Yogyakarta \\ halimahfebriyani25@gmail.com
}

\begin{tabular}{|c|c|c|}
\hline Submited: & Revision Required: & Published: \\
15 April 2021 & 20 Mei 2021 & 15 Juni 2021 \\
\hline
\end{tabular}

\begin{abstract}
This study discusses the organization of 'Aisyiyah during the leadership of Siti Baroroh Bared, in which in her leadership she succeeded in making 'Aisyiyah known and collaborating with international organizations. This article will reveal the condition of 'Aisyiyah before the leadership of Siti Baroroh Bared and how the development of 'Aisyiyah during her leadership. The method used in this research is the historical method. Siti Baroroh Bared has a high intellect so that she can create superior and new programs in an 'Aisyiyah organization including the development of the Bustanul Athfal Kindergarten, establishing a school for midwives and nurses, conducting recitations by traveling outside the Kauman village, the existence of an Economic Business Entity program The 'Aisyiyah family (BUEKA), conducts regeneration and leadership coaching and training programs, organizes compensation programs for orphans and the poor, in addition to cooperating with various parties or organizations and establishing several federations of women's organizations
\end{abstract}

Keywords: modernisation, 'aisyiyah, leadership, development 


\begin{abstract}
Abstrak
Penelitian ini membahas organisasi 'Aisyiyah masa kepemimpinan Siti Baroroh Baried, yang mana dalam kepemimpinannya ia berhasil menjadikan 'Aisyiyah dikenal dan menjalin kerjasama dengan organisasi Internasional. Dalam artikel ini akan diungkapkan kondisi 'Aisyiyah sebelum kepemimpinan Siti Baroroh Baried dan bagaimana perkembangan 'Aisyiyah pada masa kepemimpinannya. Metode yang digunakan dalam penelitian ini adalah metode sejarah. Siti Baroroh Baried memiliki intelektualitas yang tinggi sehingga ia dapat membuat program unggulan dan baru dalam sebuah organisasi 'Aisyiyah diantaranya pengembangan Taman Kanak-kanak Bustanul Athfal, mendirikan sekolah bidan dan perawat, mengadakan pengajian dengan cara melakukan perjalanan keluar kampung Kauman, adanya program Badan Usaha Ekonomi Keluarga 'Aisyiyah (BUEKA), mengadakan program pembinaan dan pelatihan kaderisasi dan kepemimpinan, mengadakan program santunan kepada anak yatim dan fakir miskin, selain itu juga menjalin kerjasama dengan berbagai pihak atau organisasi dan mendirikan beberapa federasi organisasi perempuan.
\end{abstract}

Kata Kunci: modernisasi, ‘aisyiyah, kepemimpinan, perkembangan

\title{
PENDAHULUAN
}

Siti Baroroh Baried terpilih menjadi ketua umum 'Aisyiyah pada periode tahun 1965, dan terpilih kembali selama 5 periode berturut-turut yakni 1965-1968, 1968-1971, 1971-1974, 1974-1977 dan 1977-1985 M (Muham madiyah, Suara 'Aisyiyah, 1965). Pada tahun yang sama yakni tahun 1965 saat Muktamar ke-36 di Bandung, ia dan salah seorang dari 'Aisyiyah yakni Siti Aisyiah Hilal masuk sebagai anggota Pimpinan Pusat Muhammadiyah periode 1965-1968 (Muhammadiyah, 95 Tahun Langkah Perjuangan Muhammadiyah, 1975).Dalam hal ini menandai optimisme Muhammadiyah dengan adanya suatu gerakan yang menyangkut gender dengan adanya partisipasi perempuan dalam keanggotaan Muktamar yang mana pada masa sebelumnya belum 
Vol. 1, No. 1, Juni 2021: h.21-45. DOI: xxxxxx/jih.v\{\}i\{\}.\{\}

pernah ada partisipasi perempuan di dalamnya (Muhammadiyah, 95 Tahun Langkah Perjuangan Muhammadiyah, 1975). Masuknya Siti Baroroh Baried dalam jajaran Pimpinan Muhammadiyah memberikan dampak yang positif bagi organisasi 'Aisiyah, yakni adanya perubahan status 'Aisyiyah menjadiorganisasi otonom pada tahun 1966 ('Aisyiyah, Sejarah Pertumbuhan dan Perkembangan 'Aisyiyah, tanpa tahun).

'Aisyiyah pada tahun 1965-1985 melakukan banyak aktivitas yang cukup menjadikan menarik dalam penelitian ini diantaranya 'Aisyiyah berperan aktif dalam Konferensi Islam Afrika-Asia (KIAA) pada 06-13 Maret 1965 ('Aisyiyah, Majalah Suara 'Aisyiyah, 2019). Tahun 1966 ikut mempelopori berdirinya Badan Musyawarah Wanita Islam Yogyakarta (BMWIY) yang merupakan federasi dari organisasi Wanita Islam di Daerah Istimewa Yogyakarta. Pada tahun 1967 'Aisyiyah turut memprakarsai berdirinya Badan Musyawarah Organisasi Perempuan Islam Indonesia (BMOPII) kemudian berubah nama menjadi Badan Musyawarah Organisasi Islam Wanita Indonesia (BMOIWI) ('Aisyiyah, Sejarah Pertumbuhan dan Perkembangan 'Aisyiyah, tanpa tahun, pp. 77-78). Pada masa ini 'Aisyiyah ikut serta dalam Konferensi Internasional di India tahun 1973. (Muhammadiyah, Suara Muham madiyah, ke-51 1971). 'Aisyiyah pada masa kepem impinan Siti Baroroh Baried juga turut dalam memprakasai berdirinya Badan Koordinasi Organisasi Wamita (BKOW) dengan membawa misi mubalighat (Dzaman, 2019). Selain itu 'Aisyiyah dalam membangun program-programnya menjalin relasi dengan badan-badan Internasional seperti UNICEF, UNESCO, WHO, The Asia Foundation, World Conference of Religion an Peace, UNFPA, UNDP, World Bank, dan masih banyak lainnya (Ahmad, 2019). Selain itu organisasi 'Aisyiyah juga memiliki kegiatan ekstra bagi para anggotanya yang 
bermanfaat antara lain: Tahun 1970 'Aisyiyah mengadakan Pelathan kepemimpinan organisasi bekerjasama dengan Overseas Education Fund, pelatihan kader dengan mengirim beberapa utusan ke Amerika bersama peserta dari negara-negara berkembang di Asia, Afrika dan Amerika Latin. Tahun 1972 'Aisyah menjalin kerjasama dengan Pathfinder Foundation mengadakan sosialisasi pentingnya keluarga sejahtera, yang memotivasi para ibu rumah tangga untuk bisa ikut menyokong perekonomian rumah tangga dengan melakukan hal produktif. Mengadakan Program Pembinaan Wanita Desa (PWD) dilatih dasar-dasar kepemimpinan untuk mewujudkan Keluarga Sakinah (Setiawati, 2019).

Beberapa hal yang dapat ditelusuri sehubungan dengan penelitian ini antara lain. Pertama, Aisyiyah pada tahun 1965-1985 M, mampu membawa kemajuan bagi kaum perempuan dengan keikutsertaan dan aktivitasnya dalam berbagai organisasi didunia nasional maupun Internasional. Kedua, aktivitas ini merupakan sebuah gerakan atau dapat dikatakan sebagai sejarah pergerakan perempuan yang mana memang sudah banyak dilakukan, nam un saat ini sejarah perempuan masih tertinggal dengan ilmu-ilmu sosial. Ketiga, Pengkajian sejarah 'Aisyiyah ini dilakukan sebagai usaha-usaha untuk menambah penulisan sejarah pergerakan perempuan. Maka dari itu penulis menarik untuk melakukan kajian ilmiah terhadap kajian tersebut secara gambling dengan eksplanasi konkret dengan tiga problematika akademik (rumusan masalah) yakni: Bagaimana kondisi 'Aisyiyah sebelum kepemimpinan Siti Baroroh Baried?. Siapa Siti Baroroh Baried? Bagaimana perkembangan 'Aisyiyah pada masa kepem im pinan Siti Baroroh Baried? Adapun tujuan penelitian ini untuk: menarasikan sejarah ‘Aisyiyah pada masa kepem impinan Siti Baroroh 
Vol. 1, No. 1, Juni 2021: h.21-45. DOI: xxxxxx/jih.v\{\}i\{\}.\{\}

baried, menganalisis perekmbangan aktivitas yang dilakukan pada masa Kepemipinannya dan menjelaskan faktor pendukung dan penghambat aktivitasnya selama masa Kepemimpinan Siti Baroroh Baried.

\section{TEORI DAN METODOLOGI}

Teori yang digunakan dalam penelitian ini adalah teori strukturalfungsional yang dikemukan oleh Talcott Parsons. Teori ini berasumsi bahwa suatu masyarakat terdiri atas beberapa bagian yang mempengaruhinya. Teori struktural-fungsional mengakui adanya keragaman dan kehidupan sosial. Keragaman yang dimaksudkan dalam teori ini adalah sumber utama adanya struktur masyarakat dan menentukan keragamanfungsi sesuai dengan posisi seseorang dalam struktur yang ada pada sebuah sistem. Hal tersebut dapat kita lihat misalnya pada sebuah organisasi pasti ada anggota yang mampu menjadi pemimpin, sekretaris, bendahara, dan anggota. Perbedaan fungsi dalam organisasi ini bertujuan untuk mencapai tujuan bersama dalam organisasi, bukan tujuan individu yang ada dalam organisasi. (Marzuki, 2007:4(1)).

Pendekatan yang digunakan adalah pendekatan sosiologi. Dalam sejarah dimaksudkan dalam upaya pemahaman dan penjelasan terhadap perilaku-perilaku sosial. Perilaku sosial yang ini erat kaitannya dengan usaha-usaha yang dilakukan oleh suatu gerakan. Hal ini untuk memperhatikan fenomena-fenomena yang terjadi dalam masyarakat Hubungan yang terjalin antara anggota maupun pengurus 'Aisyiyah dalam suatu situasi dan kondisi yang dapat mengungkapkan keadaan masyarakat dan gejala-gejala aspek sosial. 
Metode dalam penelitian ini menggunakan metode sejarah yang mada metode penelitan dan penulisan sejarah dengan menggunakan cara,prosedur yang sistematik sesuasi dengan asas-asas dan aturan ilmu sejarah. Metode penelitian sejarah meliputi em pat tahapan; Tahap pertama pengumpulan sumber (heuristik) peneliti mencari dan mengumpulkan sumber primer berupa arsip, hasil Muktamar dan foto kegiatan tahun 1965-1985 M, Sedangkan sumber sekunder berupa buku, skripsi, artikel dan Jurnal dari beberapa Perpustakaan UIN Sunan Kalijaga, Perpustakaan 'Aisyiyah, Perpustakaan Ignatius, Perpustakaan Muhammadiyah, Perpustakaan Universitas Muhammadiyah Yogyakarta, Perpustakaan Universitas Gajah Mada, dan Perpustakaan Grahatama Pustaka. Sumber lain berupa wawancara terpim pin yang dilakukan kepada anggota 'Aisyiyah dan keturunan Siti Baroroh Baried. Hal selanjutnya adalah verifikasi, sumber yang telah ditemukan dikritisi dengan cara kritik intern dan ekstern. Tahapan selanjutnya adalah interpretasi yang mana peneliti berusaha menafsirkan fakta-fakta yang didapatkan. Terakhir yakni Historiografi, penulisan atau pelaporan hasil.

Penelitian mengenai 'Aisyiyah sebagai gerakan perempuan Muhammadiyah sudah banyak dilakukan oleh karya-karya terdahulu, akan tetapi karya-karya tersebut masih bagian kecil dari pembahasan mengenai peregerakan perepuan, penelitian ini akan difokuskan pada aspek tertentu, namun objek yang di kaji sama. Maka peneliti melakukan sebuah penelusuran pustaka terdahulu yang terkait dengan tema gerakan perempuan Islam di Indonesia peneliti telah menemukan beberapa karya sebagai berikut: Pertama, buku dengan judul Posisi dan Jatidiri 'Aisyiyah karya Rof'ah yang diterbitkan di Yogyakarta oleh penerbit Suara Muhammadiyah tahun 2016. Buku tersebut 
Vol. 1, No. 1, Juni 2021: h.21-45. DOI: xxxxxx/jih.v\{\}i\{\}.\{\}

menjelaskan mengenai seluk beluk sejarah pembentukan, aktivisme, dan evolusi 'Aisyiyah, selain itu buku ini juga menjelaskan mengenai aspek sejarah berdirinya 'Aisyiyah, juga menjelaskan bagaimana perkem bangan 'Aisyiyah pada masa Orde Lama dan Baru. Keterkaitan dengan penelitian ini adanya pembahasan 'Aisyiyah pada masa kepemimpinan Siti Baroroh Baried. Dengan ini maka dapat diperoleh informasi perkembangan 'Aisyiyah ketika masa kepemimpinan Siti Baroroh Baried. Perbedaan pada penelitian ini menjelaskan mengenai 'Aisyiyah pada masa kepemipinan Siti Baroroh Baried tahun 1965-1985 M.

Kedua, buku dengan judul Sejarah Kauman karya Pimpinan Pusat Muhammadiyah yang diterbitkan di Yogyakarta. Buku ini mengungkapkan tentang sejarah kampung Kaumanmengenai sejarah lahirnya, masyarakatnya, kehidupan masyarakatnya, perkumpulan organisasi-organisasi yang lahir di Kauman dan reformasi dan perubahan sosial dalam masyarakat Kauman. Keterkaitan dengan penelitian ini adanya pembahasan mengenai Sejarah Kauman dan sekilas mengenai berdirinya 'Aisyiyah. Dengan ini maka diperoleh informasi mengenai seluk beluk masyarakat Kauman dan bagaimana lahirnya organisasi 'Aisyiyah. Perbedaan pada penelitian ini membahas mengenai 'Aisyiyah pada masa kepemipinan Siti Baroroh Baried tahun 1965-1985 M.

Ketiga, buku dengan judul Srikandi-srikandi 'Aisyiyah karya Mu'arif dan Hajar Nur Setyowati yang diterbitkan di Yogyakarta oleh penerbit Suara Muhammadiyah tahun 2014. Buku ini secara umum membahas mengenai tokoh organisasi 'Aisyiyah pada masa awal, yakni Siti Bariyah, Siti Munjiyah, Siti Umniyah, Siti Walidah, Siti Aisyah, Siti Hayinah dan Siti Badilah. Buku ini mempunyai keterkaitan dengan 
penelitian ini dalam menjelaskan tokoh-tokoh perempuan sebelum masa kepemimpinan Siti Baroroh Baried. Meskipun penjelasan mengenai kepemimpinan Siti Baroroh Baried tidak ada, namun penelit sedikit banyak mendapat informasi mengenai gambaran kepem im pinan sebelum masa kepemimpinan Siti Baroroh Baried. Oleh karena itu, penelitian ini berusaha melanjutkan dan melengkapi dari karya buku terdahulu.

Keempat, skripsi dengan judul "Kiprah Siti Hajinah Mawardi di 'Aisyiyah tahun 1946-1965" yang ditulis oleh Herlinda Rahmawati (mahasiswa Jurusan Sejarah dan Kebudayaan Islam Fakultas Adab dan IImu Budaya Universitas Islam Negeri Sunan Kalijaga Yogyakarta, 2016). Skripsi ini membahas mengenai 'Aisyiyah pada masa Siti Hajinah Mawardi tersebut secara umum membahas mengenai kiprah Siti Hajinah Mawardi di 'Aisyiyah pada saat ia menjabat sebagai ketua umum selama beberapa periode pada tahun 1946-1965. Tahun 1946 merupakan awal kepemimpinan Siti Hajinah Mawardi dan tahun 1965 merupakan akhir kepemimpinan Siti Hajinah Mawardi. Keterkaitan skripsi tersebut dengan penelitian ini adalah sama-sama membahas mengenai tokoh perempuan 'Aisyiyah. Dengan penjelasan tersebut, peneliti memperoleh cukup informasi mengenai dinamika 'Aisyiyah sebelum kepemimpinan Siti Baroroh Baried. Perbedaan dengan karya ini adalah pada subjek kajiannya. Pada karya tersebut difokuskan pada Siti Hajinah dan kiprahnya sedangkan penelitian ini lebih kepada 'Aisyiyah pada masa kepem impinan Siti Baroroh Baried.

Kelima skripsi dengan judul "Peran 'Aisyiyah dalam Internalisasi Nilai-nilai Muhammadiyah di Kampung Kauman Yogyakarta” yang ditulis oleh Latifah Hayati, mahasiswa Fakultas Ushuluddin dan Pemikirian Islam, Universitas Islam Negeri Sunan Kalijaga Yogyakarta. 
Vol. 1, No. 1, Juni 2021: h.21-45. DOI: xxxxxx/jih.v\{\}i\{\}.\{\}

Skripsi tersebut fokus membahas proses historis lahirnya 'Aisyiyah pada tahun 1917 dan gambaran umum Kauman, sejarah dan latar belakang Kauman serta keadaan demografi Kauman. Keterkaitan karya tersebut dengan penelitian ini adalah pembahasan mengenai gambaran umum Kampung Kauman, Sejarah dan latar belakang Kauman serta keadaan demografi. Perbedaanya pada fokus kajian karya tersebut membahas mengenai 'Aisyiyah yang ada di Kauman yang menjadi barometer organisasi 'Aisyiyah cabang lainnya, khususnya dalam perannya terhadap proses internalisasi nilai-nilai Muham madiyah.

Keenam, skripsi dengan judul "Kiprah Siti Bariyah di 'Aisyiyah tahun 1917-1929 M" yang ditulis oleh Anjas Pratiwi, mahasiswa Fakultas Adab dan IImu Budaya, Universitas Islam Negeri Sunan Kalijaga Yogyakarta. Skripsi tersebut fokus membahas mengenai kiprah Siti Bariyah pada saat menjabat sebagai ketua yakni tahun 19171929 M. Skripsi tersebut mempunyai keterkaitan dengan penelitian ini karena di dalam bahasan mengenai salah satu ketua yakni Siti Bariyah ketika menjadi ketua 'Aisyiyah. Dengan penjelasan mengenai kiprah Siti Bariyah tersebut, peneliti memperoleh cukup informasi mengenai perkembangan organisasi 'Aisyiyah sebelum masa kepemimpinan Siti Baroroh Baried. Dengan demikian, perbedaan antara karya tersebut dengan penelitian ini terletak pada fokus subjek kajian. Pada karya tersebut lebih fokus kepada Kiprah Siti Bariyah saat mempimpin 'Aisyiyah. Penelitian ini berfokus pada kepemiminan ' Aisyiyah pada masa Siti Baroroh Baried.

Secara spesifik, perbedaan penelitian ini dengan karya-karya di atas, terletak pada sekup temporal dan fokus kajian yang diteliti. Fokus penelitian ini membahas mengenai perkembangan 'Aisyiyah pada 
tahun 1965-1985 M. Tepatnya yaitu selama lima periode dibawah kepemimpinan Siti Baroroh Baried. Dalam hal ini karena pada masa kepemimpinan Siti Baroroh Baried, mengalami kemajuan yang signifikan dari kepemimpinan sebelumnya khususnya dalam bidang pendidikan dan kaderisasi, bidang keagamaan, bidang sosial dan bidang ekonomi. Hal ini menunjukkan pentingnya penelitian dalam fokus kajian tersebut, agar usaha-usaha yang dilakukan oleh 'Aisyiyah khususnya dapat memberikan bukti bahwa kaum perempuan mampu memperkuat agama Islam yang berbeda dari kaum lelaki. Mereka dapatmensukseskan programnya, program pemerintah dan membantu program Muhammadiyah. Penelitian ini juga memberikan pandangan bahwa kaum perempuan pada masaitu mampu memberikan kemajuan bagi kaum perempuan.

\section{PEMBAHASAN}

\section{'Aisyiyah Sebelum Kepemimpinan Siti Baroroh Baried}

Latar belakang berdirinya 'Aisyiyah tidak dapat lepas dari peran K.H. Ahmad Dahlan sebagai pelopor dalam gerakan pembaharuan di Kauman. Pada tahun 1917, pengurus Muhammadiyah yakni K.H. Ahmad Dahlan, K.H. Fachrodin, K.H. Mochtar, dan Ki Bagus Hadikusuma beserta keenam gadis yakni Siti Dawimah, Siti Dalalah, Siti Busjro, Siti Wadingah, dan Siti Badilah mengadakan pertemuan. Dalam pertem uan tersebut diputuskanlah berdirinya organisasi wanita dalam tubuh Muhammadiyah (Darban, 2010). Dan diberi nama 'Aisyiyah¹, dan resmi berdiri pada tanggal 22 April 1917 (Muarif, 2014).

\footnotetext{
${ }^{1}$ Nama 'Aisyiyah berasal dari kata Aisyah, yaitu nama salah satu istri Nabi Muhammad yang kemudian ditambah ya' nisbiyah yang berarti pengikut/pengiring. Muhammadiyah menamakan gerakan wanitanya dgn 'Aisyiyah bermaksud agar kaum ibu
} 
Pada awal tahun setelah berdirinya 'Aisyiyah sekitar tahun 1923, 'Aisyiyah mengawali program pertamanya dengan pemberantasan buta aksara yakni huruf Latin dan Arab, yang mana kegiatan ini kemudian menjadi sebuah perkumpulan yang diberi nama 'Aisyiyah Maghribi School ('Aisyiyah, Sejarah Pertumbuhan dan Perkembangan 'Aisyiyah, tanpa tahun, p. 34). Hal tersebut dilakukannya karena pada abad ke 20 pendidikan di Indonesia hanya terbatas pada angka loro, ${ }^{2}$ khususnya bagi kaum perempuan. Dan belum terbukanya kesadaran masyarakat akan pendidikan, terlebih perempuan yang dianggap hanya sebagai konco wingking ${ }^{3}$ dan tidak memerlukan pendidikan tinggi. Melalui program ini 'Aisyiyah menginginkan pemberantasan buta aksara pada perem puan khususnya yang berada di Kampung Kauman. Kemudian tahun 1926 'Aisyiyah mulai mengembangkan organisasinya melalui media yakni majalah dan diberi nama "Suara Aisyiyah" yang terbit setiap satu bulan sekali. Pada tahun 1928 'Aisyiyah turut memprakarsai terbentuknya organisasi wanita (M. Raihan Febriansyah, 2013).

Sejak 'Aisyiyah secara resmi menjadi organisasi perempuan Muham madiyah hingga saat ini, gerakan 'Aisyiyah terus berkembang pesat dan kokoh. Kiprahnya dalam belantika dunia pergerakan kaum perem puan dapat kita lihat, 'Aisyiyah berhasil membangunamal usaha dalam berbagai bidang seperti bidang kesehatan, perekonomian, pendidikan, dan dakwahnya. Kunci dari keberhasilan 'Aisyiyah dalam

dalam Muhammadiyah ikut berjuang bersama dalam menyampaikan ajaran Islam ke tangah masyarakat serta dapat meneladani peri kehidupan dan perjuangan ibu kaum Muslimin.

${ }^{2}$ Angka loro dalam bahasa Jawa mempunyai arti angka dua. Maksdunya adalah tingkatan kelas yang hanya terdiri dari kelas satu hingga kelas dua.

${ }^{3}$ Konco Wingking adalah teman untuk urusan rumah tangga saja. 
mencapai setiap tantangan zaman adalah peran serta para tokoh yang memimpin.

Kepemimpinan sebelum Siti Baroroh Baried yakni Masa Kepem impinan Siti Bariyah (1917-1920 M), selanjutnya kepemimpinan Siti Walidah (1921-1926 M), Kepemimpinan Siti Bariyah (1927-1929 M), Kepemimpinan Siti Walidah (1930 M), Kepemimpinan Siti Aisyah (1931 M), Kepemimpinan Siti Munjiah (1932-1936 M), Kepemimpinan Siti Aisyah (1937 M), Kpemimpinan Siti Badilah (1938 M), Kepem impinan Siti Aisyah (1939-1945 M), Kepemimpinan Siti Hajinah Mawardi (1946-1965 M).

\section{Sosok Baroroh Baried sebagai Pimpinan 'Aisyiyah}

Siti Baroroh baried lahir di Kampung Kauman, Yogyakarta, pada tanggal 23 Mei 1923 (Indiyanto, 2019), dan wafat pada tanggal 9 Mei 1999. Siti Baroroh Baried merupakan putri bungsu dari H. Tamim bin Dja'far dan Siti Asmah binti Haji Muhammad. la merupakan putri bungsu dari tiga bersaudara, yaitu Daris Tamimi dan Jindar Tamimi. Ayahnya merupakan kemenakan dari Siti Walidah, istri pendiri Muham madiyah (Ahmad, 2019). Baroroh menikah dengan dr. Baried Ishom, sehingga namanya mengikuti nama suaminya menjadi Siti Baroroh Baried. Siti Baroroh menggunakan nama suaminya untuk nama belakangnya karena pada saat itu, sebagian dari istri yang aktif dalam Muhammadiyah mengambil nama suami untuk nama belakangnya. Hal ini untuk memudahkan untuk dikenali. Pernikahannya dengan dr. Baried tanggal 31 Januari sekitar tahun 1956 atau 1960. Siti Baroroh tidak memiliki putra, namun ia merawat dua orang anak dari saudaranya yakni Fery Indiyanto dan Ella Elfira. 
Vol. 1, No. 1, Juni 2021: h.21-45. DOI: xxxxxx/jih.v\{\}i\{\}.\{\}

Siti Baroroh Baried memulai pendidikannya di SD Muhammadiyah, kemudian melanjutkan di Meer Uitgebreid Lager Onderwijs (MULO HIK) Muhammadiyah. Tahun 1952 ia meraih gelar sarjana Fakultas Sastra Universitas Indonesia di Jakarta. Kemudian ia memutuskan untuk melanjutkan kuliah di Universitas Al Azhar Mesir (1953-1955), bukan tanpa alasan ini merupakan suatu wujud perjuangan sekaligus pembuktiannya dalam hal emansipasi wanita. Pada saat itu, langka terjadi perempuan bisa mengenyam pendidikan di luar negeri. Kemauan kuatnya telah mengantarkan ia menjadi profesor perem puan pertama di Indonesia.

Pada tahun 1964 Siti Baroroh Baried diangkat menjadi guru besar dalam IImu Bahasa Indonesia. Hal tersebut ia lakukan karena sejak muda Siti Baroroh Baried memiliki semboyan "Hidup saya harus menuntut IImu". Itulah yang menjadi dasar bagi ia untuk membuktkan bahwa perem puan dapat menempuh pendidikan setinggi mungkin. Hal tersebut menunjukkan peran Siti Baroroh dalam dunia pendidikan. Sejak itu beliau mulai mengajar di berbagai universitas negeri maupun swasta. Beliau mengajar di Universitas Gadjah Mada Fakultas Sastra sejak tahun 1949 ('Aisyiyah, www.'Aisyiyah .or.id, 2018). Selain sebagai pengajar di Fakultas Sastra UGM, la juga sebagai anggota Komisi Kerja Senat Fakultas Sastra UGM, dosen IAIN ( UIN) Sunan Kalijaga. Dosen luar biasa di IKIP (UNY), Guru besar Universitas Muhammadiyah Surakarta dan Dewan Penyantun Universitas Muhammadiyah Yogyakarta. Siti Baroroh pernah menjabat dekan Fakultas Sastra UGM selama dua periode yakni tahun 1965-1968 dan 1968-1971. Kemudian menjadi Ketua Jurusan Asia Barat Fakultas Sastra UGM 1963-1975 (Lasa HS, 2014). 
Siti Baroroh Baried dibesarkan di lingkungan Muhammadiyah ayahnya, merupakan kemenakan dari Nyai Ahmad Dahlan istri pendiri Muhammadiyah dan juga sebagai pengurus Muhammadiyah. Hal tersebut menjadi penting karena dimulai sejak kecil, ia telah aktif dalam beberapa organisasi Muhammadiyah maupun 'Aisyiyah. Beberapa amanat diembannya mulai dari Ketua Pimpinan Cabang 'Aisyiyah Gondomanan, dan dalam Pimpinan pusat 'Aisyiyah ia pernah menjabat sebagai Ketua Biro Hubungan Luar Negeri, Ketua Biro Penelitian dan Pengembangan dan Ketua Bagian Paramedis. Kemudian aktivitas dalam organisasi Muhammadiyah adalah ketika ia masuk pada jajaran Pimpinan Muhammadiyah, pada masa kepemimpinan K.H. Junus Anis. Saat itu ia adalah dua diantara perem puan yang masuk pada jajaran Muhammadiyah (Muhammadiyah, 95 Tahun Langkah Perjuangan Muham madiyah, 1975, p. 177). Dan pada tahun 1999 ia masuk menjadi penasihat ahli Majelis Tarjih dan Pengembangan Pemikiran Islam Pimpinan Pusat Muhammadiyah. Siti Baroroh juga aktif dalam organisasi seperti Majelis Ulama Indonesia Pusat (MUI) dan Ikatan Cendekiawan Muslim Indonesia (ICMI) ('Aisyiyah, www.'Aisyiyah.or.id, 2018).

Selain aktivitas dalam Muhammadiyah Siti Baroroh juga memiliki andil dalam kancah dunia Internasional, maupun Nasional. Salah satunya di Harvard University, Amerika Serikat, yang mana ia menyampaikan materi mengenai "Aisyiyah and The Social Change Woman of Indonesian". Dan ia selalu membawa nama 'Aisyiyah dalam forum-forum global, sehingga nama 'Aisyiyah mulai dikenal dalam kancah dunia Internasional yang menimbulkan adanya jalinan relasi dengan beberapa pihak seperti UNICEF, UNESCO,WHO, The Asia 
Vol. 1, No. 1, Juni 2021: h.21-45. DOI: xxxxxx/jih.v\{\}i\{\}.\{\}

Foundation, World Conference of Religion and Peace, UNFPA, UNDP, World Bank, dan masih banyak lainnya (Setiawati, 2019, pp. 22-23).

Siti Baroroh Baried tidak hanya aktif dalam bidang organisasiorganisasi saja, namun ia juga aktif dalam bidang akademisi. Hal ini dapat kita lihat pada aktivitas ia saat menjadi pengajar di beberapa perguruan tinggi negeri maupun swasta. Beberapa riwayat beliau dalam bidang akademisi, yakni tahun 1949 Siti Baroroh Baried mulai mengajar di Universitas Gadjah Mada(UGM) Yogyakarta, Tahun 19631975 beliau menjadi Ketua Jurusan Asia Barat Fakultas Sastra UGM Yogyakarta dan pada tahun 1964 beliau diangkat menjadi guru besar dalam IImu Bahasa Indonesia.Selama dua periode yakni tahun 19651968 dan 1968-1971 ia menjadi dekan Fakultas Sastra UGM ('Aisyiyah, www.'Aisyiyah.or.id, 2018).

Siti Baroroh Baried dengan kapasitasnya sebagai akademis, cendekiawan dan ulama telah banyak menulis berbagai karya ilmiah dengan berbagai tema. la menuangkan pemikirannya dalam karya tulis maupun buku. Beberapa buku yang ditulisnyaantara lain: Bahasa Arab dan Perkembangannya dalam Bahasa Indonesia tahun 1970, Kamus Istilah Filologi tahun 1977, Memahami Karya-karya Nuruddin ar-Raniry tahun 1982, dan Pengantar Teori Filologitahun 1985. Selain itu Siti Baroroh juga menulis makalah antara lain : Un Movement des Femmes Musulmans Aisyiyah tahun 1977 dalam Archipel 13; La Slancio Riformista tahun 1981 dalam Corriere XLIV, No*9, Roma; dan Moslem Women and Social Change in Indonesia: The Work of Aisyiyah tahun 1987 dalam Speaking of Faith (Lasa HS, 2014, p. 59). Karya Siti Baroroh tentang perempuan dengan judul Islam dan Modernisasi Wanita Indonesia dalam buku Tradisi dan Kebangkitan Islam di Asia Tenggara (Taufik Abdullah, 1989). 


\section{'Aisyiyah pada Masa Kepemimpinan Siti Baroroh Baried}

Siti Baroroh Baried terpilih sebagai Pimpinan Pusat 'Aisyiyah selama lima periode tepatnya mulai tahun 1965 hingga 1985 M. Siti Baroroh terpilih ketika diadakannya Muktamar Muhammadiyah yang ke-36 di Bandung tahun 1965. Dalam organisasi Muhammadiyah, organisasi 'Aisyiyah mendapat waktu khusus untuk membahas program kerja dan kepengurusan. la terpilih selama lima periode dengan satu cara yakni ditunjuk dengan dukungan dari Pengurus Pusat Muhammadiyah dan semua anggota 'Aisyiyah. Selain sebagai Pimpinan Pusat 'Aisyiyah, ia masuk pada jajaran Pengurus Pimpinan Pusat Muhammadiyah. Adapun Keputusan Muktamar Muhammadiyah dan Muktamar 'Aisyiyah ketika Siti Baroroh terpilih yaitu, Pada Muktamar 'Aisyiyah ke-36 pada 19 hingga 24 Juli 1965 di Bandung, mengajukan beberapa usulan. Usulan tersebut antara lain Pimpinan Pusat Muhammadiyah supaya mengusahakan M.P.H Wanita dan dalam Muhammadiyah mengadakan kerjasama tingkat pusat supaya memperhatikan pelaksanaanya sampai kebawah.

Pada Muktamar selanjutnya yakni Muktamar ke 37 tahun 1968 di Yogyakarta hingga Muktamar ke 40 di Surabaya, Siti Baroroh Baried masih diperlukan kepempinannya oleh 'Aisyiyah, sehingga ia terpilih secara berturut-turut selama lima periode lamanya (Muhammadiyah, Suara Muhammadiyah, ke-51 1971). Hal ini dikarenakan programprogram 'Aisyiyah pada masa awal ia menjabat belum terlihat atau masih dalam proses realisasi, oleh karenanya anggota 'Aisyiyah yang lain memilih beliau agar program-program kerja pada masa awal ia menjabat dapat dilaksanakan dengan baik (Dzaman, 2019). 
'Aisyiyah pada masa kepemimpinan Siti Baroroh Baried tepatnya tahun 1965-1985 M selama lima periode mengalami kemajuan yang pesat dari sebelumnya. Dapat dikatakan pada masa kepemimpinan Siti Baroroh merupakan tombak awal dari sebuah pembaharuan atau penyegaran bagi suatu organisasi. Pada masa ini 'Aisyiyah mulai berkiprah dalam berbagai bidang, diantaranya yaitu: Bidang Pendidikan, Masa kepemimpinan Siti Baroroh Baried ia melakukan beberapa pengembangan dalam dunia pendidikan dan kaderisasi diantaranya :a.) Pengembangan Taman Kanak-Kanak, Pada masa kepem im pinan Siti Baroroh Baried ia mengem bangkan Taman Kanakkanak 'Aisyiyah Bustanul Athfal dengan cara mengkoordinasi selunuh bagian-bagian yang terdapat pada Cabang 'Aisyiyah untuk mendirikan pra sekolah di daerah Pimpinan Cabang tersebut (Dzaman, 2019). Hingga saat penelitian iniberlangsung, yakni tahun 2019, TK ABA telah mencapai jumlah 5.865 TK di seluruh Indonesia (Muhammadiyah, Majalah Suara Muhammadiyah, ke-60). b.) Mendirikan Sekolah Kebidanan dan Perawat, Pada Muktamar ke-39 di Padang tahun 1975 memutuskan bahwa partisipasi 'Aisyiyah ke masyarakat, diminta agar mengusahakan sekolah perawat bidan. Sekolah ini mendidik calon bidan berasal dari daerah yang nantinya dapat mengabdikan dirinya di daerahnya masing-masing. Maka dengan itu diadakannya kerjasama antara PKU Muhammadiyah Jogja dengan negeri belanda NOVIB, guna untuk mendirikan asrama para medis. Pendirian asrama para medis ini didirikan oleh PKU Muhammadiyah, namun pengasuhan dan merawatnya diserahkan kepada PP ‘Aisyiyah ('Aisyiyah, Majalah Suara 'Aisyiyah, ke-50).

\section{Bidang Kaderisasi}


Pada masa kepeimpinan Siti Baroroh melalui muktamar ke-37 tahun 1968 'Aisyiyah memutuskan untuk membentuk biro Kaderisasi ('Aisyiyah, Sejarah Pertumbuhan dan Perkembangan 'Aisyiyah, tanpa tahun, p. 72). Hal ini dengan cara mengirimkan beberapa kader-kader 'Aisyiyah untuk mengikuti pelatihan kepemimpinan organisasi yang bekerjasama dengan Overseas Education Fund, Tiap tahun 'Aisyiyah mengutus 2 hingga 3 kader terbaik untuk dikirim ke Amerika bersama dengan negara-negara berkembang di Asia, Afrika, dan Amerika Latin, Mengadakan sosialisasi pentingnya keluarga sejahtera pada tahun 1972 yang bekerjasama dengan Pathfinder Foundation, Mengadakan pelatihan Program pembinaan Wanita Desa (Ahmad, 2019). Pada masa kepemimpinan Siti Baroroh Baried, ia melakukan kaderisasi dengan cara langsung yaitu dengan memberikan pembinaan kepada salah satu kader, yakni Ibu Ellyda Djazman yang nantinya akan meneruskan perjuangan dalam memimpin 'Aisyiyah. Ellyda Djazman pada tahun 1982 ikut serta dalam perjalanan dakwah ke Makasar. Seusai Siti Baroroh Baried menyampaikan pidato pada saat itu, ia memberikan kesempatan kepada Ellyda Djazman untuk meneruskan pidatonya, tanpa persiapan yang matang dan mendadak Ellyda Djazman meneruskan pidato Baroroh Baried. Hal tersebut dilakukan oleh Siti Baroroh Baried agar kadernya siap untuk menjadi penerus dalam memimpin ‘Aisyiyah (Dzaman, 2019).

\section{Bidang Keagamaan}

Pada masa kepemimpinan Siti Baroroh Baried kegiatan keagamaan yang ia lakukan adalah dengan cara lisan atau menyampaikan melalui pengajian-pengajian atau biasa dikenal dengan nama Mubalighat. Kegiatan ini dalam organisasi 'Aisyiyah dikenal dengan metode 
Vol. 1, No. 1, Juni 2021: h.21-45. DOI: xxxxxx/jih.v\{\}i\{\}.\{\}

Dakwah bil Lisan. Sifat dakwah yang dilakukanoleh Siti Baroroh Baried adalah pembinaan, seperti pembinaan wanita desa, pembinaan keluarga sejahtera, dll (Dzaman, 2019). Dakwah yang dilakukan 'Aisyiyah diarahkan kepada pemahaman ajaran agama Islam secara terpadu, tidak sepotong-potong, pengamalannya berdasarkan AlQur'an dan Sunnah. 'Aisyiyah melakukan purifikasi (pemurnian)ajaran Islam dari pengaruh yang bukan Islam. Ajaran Islam harus terbebaskan dari tahayul, bid'ah, dan churafat (TBC) ('Aisyiyah, Profil Mubalighat 'Aisyiyah, 2002).

\section{Bidang Ekonomi}

Pada masa kepemimpinan Siti Baroroh Baried tahun 1974 kegiatan ekonomi ini mulai diaktifkan kembali menjadi Bagian Ekonomi yang mempunyai status sama seperti bagian lainnya. Selain diaktifkan kembali Bagian Ekonomi memiliki tugas membantu meningkatkan usaha anggota 'Aisyiyah. Bentuk kegiatan ini diberi nama Badan Usaha Ekonomi Keluarga 'Aisyiyah (BUEKA) yang memiliki beberapa bagian diantaranya Pendidikan Keterampilan melalui Pengajian, Pengkoordinasi hasil usaha/produksi anggota, Penjualan produksi (pemasaran), Sewa menyewa atau simpan pinjam dan Pelatihan manajemen Usaha ('Aisyiyah, Sejarah Pertumbuhan dan Perkembangan 'Aisyiyah, tanpa tahun, p. 68).

\section{Bidang Sosial}

Masa kepemimpinan Siti Baroroh Baried menjalin berbagai hubungan sosial demi kemajuan program 'Aisyiyah, diantara nya :

Memprakarsai Berdirinya Organisasi Perempuan

Pada masa kepemimpinan Siti Baroroh Baried tahun 1966 'Aisyiyah mempelopori berdirinya Badan Musyawarah Wanita Islam Yogyakarta 
(BMWIY) yang merupakan federasi dari organisasi wanita Islamdi Daerah Yogyakarta dalam melaksanakan kegiatan bersama. Tahun 1967 'Aisyiyah juga mempelopori berdirinya Badan Musyawarah Organisasi Perempuan Islam Indonesia (BMOPII) yang kemudian berubah nama menjadi Badan Musyawarah Organisasi Islam Wanita Indonesia (BMOIWI), suatu federasi organisasi wanita muslim yang bergerak dalam bidang agama Islam dan bersifat nasional.

Menjalin Hubungan dengan Organisasi Lain

'Aisyiyah pada masa kepemimpinan Siti Baroroh Baried membuka banyak kerjasama dengan berbagai pihak, baik dari organisasi nasional maupun internasional.

Hubungan dengan Organisasi Nasional

'Aisyiyah menjadi anggota Komite Naional Kedudukan Wanita atau KNKWI dan menjadi anggota Musyawarah Perguruan Swasta (PWS). Kemudian menjalin kerjasama dengan Dewan Nasional Indonesia untuk Kesejahteraan Sosial (DNIKS) yang mana dari 'Aisyiyah diwakili oleh Bagian PKU ('Aisyiyah, Sejarah Pertum buhan dan Perkembangan 'Aisyiyah, tanpa tahun, pp. 77-78).

Hubungan dengan LuarNegeri

Masa kepemimpinan Siti Baroroh Baried menjalin hubungan dengan luar negeri dalam mensukseskan program kerja 'Aisyiyah , diantaranya: bekerjasama dengan OEF (Overseas Education Foundation) di Amerika Serikat tahun 1972-1976. Dengan berbagai program yakni Program peningkatan manajeman organisasi dan kepemimpinan, Penyusunan buku Tuntunan TK 'Aisyiyah Bustanul Athfal, Pelatihan usaha mencari dana dengan lembaga pemberi dana dari luar negen, Pelatihan manajemen organisasi 'Aisyiyah seluruh Indonesia.Dengan The Pathfinder Fund tahun 1972-1982 yakni Pengiriman 2 orang 
Vol. 1, No. 1, Juni 2021: h.21-45. DOI: xxxxxx/jih.v\{\}i\{\}.\{\}

anggota Pimpinan Pusat 'Aisyiyah untuk mengikuti Penataran Kepemimpinan Wanita di Amerika Serikat, Pelatihan tentang pendidikan kependudukan luar sekolah, Pengiriman peserta dalam pelatihan WIM (Women In Management) di AS tahun 1978, Pelaksanaan Program Wanita Desa (PWD) tahun 1978. Program lainnya menjalin kerjasama dengan NOVIB tahun 1972-1975 berupa dana untuk pembangunan Gedung sekolah bidan / perawat ('Aisyiyah, Sejarah Pertumbuhan dan Perkembangan 'Aisyiyah, tanpa tahun, pp. 78-79).

Selain menjalin hubungan dengan organisasi Internasional Siti Baroroh Baried juga menjadi bagian dalam sebuah Kongres Internasional di India. Tema konfrensi itu adalah "The Pilgrimage Towards Women's Spiritual Freedom" yang membahas mengenai empat masalah, yaitu tentang IImu pengetahuan dan Spiritualitas, Jalan Menuju Rekonstruksi Sosial, Wanita dan Perdamaian Dunia serta Pendidikan untuk Dunia Baru.Konfrensi ini dilatar belakangi oleh Vinoba Bhave 4 pada tahun 1973 yang menolak ajaran Gandhi yang dikenal masyarakat India. Gerakan yang dipelopori oleh Vinoba ini memiliki keyakinan bahwa wanita dengan segala kelembutannya itu adalah suatu sumber kekuatan yang dapat dikerahkan untuk menciptakan kasih sayang, perdamaian, dan anti kekerasan (Muham madiyah, Suara Muham madiyah, ke-51 1971).

Program Qaryah Thayyibah

Salah satu program bidang sosial yang menarik adalah Qaryah Thayyibah. Istilah ini berasal dari bahasa arab yang artinya Qaryah

\footnotetext{
${ }^{4}$ Vinoba Bhave adalah seorang advokat non-kekerasan dan hak asasi manusia India. Sering disebut Acharya, ia paling dikenal karena Gerakan Bhoodan. Ia dianggap sebagai Guru NasionalIndia dan penerus spiritual Mohandas Gandhi.
} 
adalah desa dan Thayibah adalah baik. Hal tersebut memiliki makna yakni desa atau kampung yang baik. Qaryah Thayyibah adalah sebuah program sekaligus gerakan 'Aisyiyah untuk mewujudkan tempat tinggal/tem pat hidup dalam suatu perkampungan atau desa yangmana masyarakatnya menjalankan ajaran agama Islam secara kaffah baik dalam hablun minallah \& hablun minannas. Segala aspek kehidupan yang meliputi bidang akidah, akhlak, ibadah dan mu'amalah duniawiyah (Lasa HS, 2014, p. 59).

\section{KESIMPULAN}

'Aisyiyah pada tahun 1917 resmi menjadibagian dari Muhammadiyah, pertama dipimpin Siti Bariyah. Tepatnya pada saat Musyawarah Algemene Vergadering tahun 1917 diYogyakarta. Hal yang menarik dari pemilihan ketua pertama 'Aisyiyah adalah ia tidak dapat hadir namun terpilih sebagaiketua 'Aisyiyah. Pada masa kepemimpinannya, 'Aisyiyah fokus kepada pemberantasan buta huruf dan pendirian sekolah untuk anak-anak atau sekarang lebih dikenal dengan TK ABA Bustanul Athfal.

Kepemimpinan sebelum Siti Baroroh Baried yakni Masa Kepem impinan Siti Bariyah (1917-1920 M), selanjutnya kepemimpinan Siti Walidah (1921-1926 M), Kepemimpinan Siti Bariyah (1927-1929 M), Kepemimpinan Siti Walidah (1930 M), Kepemimpinan Siti Aisyah (1931 M), Kepemimpinan Siti Munjiah (1932-1936 M), Kepemimpinan Siti Aisyah (1937 M), Kpemimpinan Siti Badilah (1938 M), Kepem impinan Siti Aisyah (1939-1945 M), Kepemimpinan Siti Hajinah Mawardi (1946-1965 M).

'Aisyiyah pada masa kepemimpinan Siti Baroroh Baried mengalami perkembangan yang pesat dari sebelumnya. Kegiatan- 
Vol. 1, No. 1, Juni 2021: h.21-45. DOI: xxxxxx/jih.v\{\}i\{\}.\{\}

kegiatan yang dilakukan oleh 'Aisyiyah merupakan upaya untuk mensejahterakan kaum perempuan. Beberapa bidang yang telah dilakukan 'Aisyiyah yaitu bidang pendidikan dan kaderisasi, bidang keagamaan, bidang ekonomi dan bidang sosial. Dalam bidang pendidikan, 'Aisyiyah melakukan beberapa program kerja yakni mengembangkan Taman Kanak-kanak 'Aisyiyah Bustanul Atfhal. Selain mengembangkan Taman Kanak-kanak 'Aisyiyah juga mendirikan Sekolah Kebidanan dan Perawat. Dalam bidang kaderisasi, pada masa tahun 1968 'Aisyiyah memutuskan untuk membentuk biro kaderisasi dengan tujuan agar anggota inti memiliki wadah dalam upaya meningkatkan intelektual dan ketrampilan, dan siap menjadi pimpinan organisasi. Dalam hal ini program yang dilakukan 'Aisyiyah adalah mengadakan pelatihan-pelatihan di wilayah-wilayah dan daerah-daerah. Dan setiap tahunnya, 'Aisyiyah mengutus atau mengirimkan beberapa kader untuk mengikuti pelatihan di berbagai negara yang menjalin kerjasama dengan 'Aisyiyah. Dalam bidang tabligh/keagamaan, 'Aisyiyah melakukan perjalanan ke beberapa desa atau wilayah dan daerah-daerah di luar Kauman, dengan cara mengirimkan mubalighat-mubalighat. Hal tersebut dilakukan agar 'Aisyiyah dapat mensyiarkan tujuan berdirinya kepada masyarakat luas. Selain itu program dalam bidang keagamaanadalah mengadakan pengajian-pengajian baik dipusat maupun ranting.

Dalam bidang ekonomi, pada masa ini 'Aisyiyah mulai mengakttifkan kembali bidang ekonominya, yakni dengan mendirikan Badan Usaha Ekonomi Keluarga 'Aisyiyah (BUEKA) yang bertugas membantu meningkatkan usaha anggota 'Aisyiyah. Dalam bidang sosial memiliki kemajuan yang sebanding dengan bidang lainnya. Pada tahun 1968 pada saat Musyawarah Kerja Nasional Muhammadiyah 
Majelis Pembina Kesejahteraan Umat memutuskan untuk mengadakan santunan keluarga 'Aisyiyah Muham madiyah. Selain itu juga 'Aisyiyah turut dalam mem prakarsai berdirinya beberapa organisasi perempuan. Dan hal yang paling penting adalah 'Aisyiyah menjalin hubungan dengan organisasi lain yang bersifat nasional dan internasional. Kerjasama ini menjadi penting karena dengan kerjasama memudahkan berbagai program yang direncanakan oleh 'Aisyiyah.

\section{REFERENCES}

Ahmad, H. (2019, Mei 23). Bagaimana sosok Siti Baroroh dan bagaimana kepemimpinnya di 'Aisyiyah. (H. N. F, Interviewer) 'Aisyiyah, P. P. (2002). Profil Mubalighat'Aisyiyah. Yogyakarta: CHasan Grafika.

'Aisyiyah, P. P. (2018, Oktober 29). Retrieved from

www.'Aisyiyah.or.id: https://aisyiyah.or.id/tokoh

'Aisyiyah, P. P. (2019, Juli). Majalah Suara 'Aisyiyah. p. 29.

'Aisyiyah, P. P. (ke-50, Juli). Majalah Suara 'Aisyiyah. p. 7.

'Aisyiyah, P. P. (ke-50, Juli). Majalah Suara 'Aisyiyah. p. 7.

'Aisyiyah, P. P. (tanpa tahun). Sejarah Pertumbuhan dan

Perkembangan 'Aisyiyah. Yogyakarta: Pimpinan Pusat 'Aisyiyah.

Darban, A. A. (2010). Sejarah Kauman: Menguak Identitas Kampung Muhammadiyah. Yogyakarta: Suara Muhammadiyah.

Dzaman, E. (2019, Agustus 6). Bagaimana sosok Siti Baroroh dan

Kepemimpinanya di 'Aisyiyah. (H. N. F, Interviewer)

Indiyanto, F. (2019, Juli 2). Kapan Kelahiran Siti Baroroh Baried. (H.

N. F, Interviewer)

Lasa HS, d. (2014). 100 Tokoh Muhammadiyah Yang Menginspirasi.

Yogyakarta: Majelis Pustaka \& Informasi PP Muhammadiyah.

M. Raihan Febriansyah, d. (2013). Muhammadiyah 100 Menyinari

Negeri. Yogyakarta: Majelis Pustaka \& Informasi PP

Muhammadiyah. 
Vol. 1, No. 1, Juni 2021: h.21-45. DOI: xxxxxx/jih.v\{\}i\{\}.\{\}

Marzuki. (2007:4(1)). Kajian Awal Tentang Teori-Teori Gender. Jurnal Civics, 70-96.

Muarif, H. N. (2014). Srikandi-srikandi 'Aisyiyah. Yogyakarta: Suara Muhammadiyah.

Muham madiyah, P. P. (1965, Oktober). Suara 'Aisyiyah. Keputusan Mu'tamar 'Aisyiyah ke-36 tahun 1965 di Bandung, p. 13.

Muhammadiyah, P. P. (1975). 95 Tahun Langkah Perjuangan

Muhammadiyah. In P. P. Muhammadiyah, Keputusan

Muktamar Muhammadiyah ke-36, tahun 1965 di Bandung ( $p$. 185). Padang: Pimpinan Pusat Muhammadiyah.

Muhammadiyah, P. P. (ke-51 1971, Mei). Suara Muhammadiyah.

Suara Muhammadiyah no.10.

Muhammadiyah, P. P. (ke-60). Majalah Suara Muham madiyah. p. 23.

Setiawati, T. (2019). Prof. Dr. Baroroh Baried \& Gerakan Perempuan

Berkemajuan. SeminarMuhammadiyah dan Kebangsaan (pp.

16-18). Yogyakarta: Universitas Muham madiyah Yogyakarta.

Taufik Abdullah, d. (1989). Tradisi dan Kebangkitan Islam di Asia

Tenggara. Jakarta: LP3ES. 